\title{
Toward standard HER2 testing of endometrial serous carcinoma: 4-year experience at a large academic center and recommendations for clinical practice
}

\author{
Natalia Buza ${ }^{1}$, Diana P English ${ }^{2}$, Alessandro D Santin ${ }^{2}$ and Pei Hui ${ }^{1}$ \\ ${ }^{1}$ Department of Pathology, Yale University School of Medicine, New Haven, CT, USA and ${ }^{2}$ Department of \\ Obstetrics, Gynecology, and Reproductive Sciences, Yale University School of Medicine, New Haven, \\ CT, USA
}

\begin{abstract}
HER2 overexpression and/or amplification have been reported in endometrial serous carcinoma, suggesting that HER2 may be a promising therapeutic target. However, there is considerable variation in the reported rates of HER2 overexpression and amplification, likely-at least in part-resulting from variability in the testing methods, interpretation, and scoring criteria used. Unlike in breast and gastric cancer, currently there are no established guidelines for HER2 testing in endometrial carcinoma. A total of 108 endometrial carcinoma cases-85 pure serous carcinomas and 23 mixed endometrial carcinomas with serous component-were identified over a 4-year period. All H\&E and HER2 immunohistochemical slides were reviewed and HER2 FISH results (available on 52 cases) were retrieved from pathology reports. HER2 immunohistochemical scores were assigned according to the FDA criteria and the current breast ASCO/CAP scoring criteria. Clinical information was retrieved from the patients' medical records. Thirty-eight cases $(35 \%)$ showed HER2 overexpression and/or gene amplification, 20 of which (53\%) had significant heterogeneity of protein expression by immunohistochemistry. Lack of apical membrane staining resulting in a lateral/basolateral staining pattern was observed in the majority of HER2-positive tumors. Five of the HER2-positive cases (13\%) demonstrated discrepant immunohistochemical scores when using the FDA versus ASCO/CAP scoring system. The overall concordance rate between HER2 immunohistochemistry and FISH was 75\% (39/52) when using the FDA criteria, compared with $81 \%(42 / 52)$ by the ASCO/CAP scoring system. In conclusion, in this largest comprehensive study, $35 \%$ of endometrial serous carcinoma harbors HER2 protein overexpression and/or gene amplification, over half of which demonstrate significant heterogeneity of protein expression. The current breast ASCO/CAP scoring criteria provide the highest concordance between immunohistochemistry and FISH. Assessment of HER2 immunohistochemistry on multiple tumor sections or sections with large tumor areas is recommended, due to the significant heterogeneity of HER2 protein expression.
\end{abstract}

Modern Pathology (2013) 26, 1605-1612; doi:10.1038/modpathol.2013.113; published online 14 June 2013

Keywords: endometrial serous carcinoma; fluorescent in situ hybridization; HER2 testing; heterogeneity; immunohistochemistry

The significance of human epidermal growth factor receptor 2 (HER2/Neu, ERBB2) amplification and HER2 protein overexpression has been well established in the pathogenesis and targeted therapy of breast cancer and more recently in gastric and

Correspondence: Dr N Buza, MD, Department of Pathology, Yale University School of Medicine, 310 Cedar Street LH 108, PO Box 208023, New Haven, CT 06520-8023, USA.

E-mail: natalia.buza@yale.edu

Received 14 March 2013; revised 8 May 2013; accepted 11 May 2013; published online 14 June 2013 gastroesophageal junction carcinomas. ${ }^{1-3}$ Tumorspecific HER2 testing guidelines have been developed to reflect the unique biological features of each of these tumor types and to predict the clinical response to HER2-targeted therapy. ${ }^{4-7}$ Although HER2/neu has been studied in endometrial cancer for over 15 years, standard testing methods or scoring guidelines are yet to be developed. The reported rates of HER2 overexpression in endometrial serous carcinoma range between 14 and $80 \%$, due to-at least in part-the significant variation in the HER2 testing 
methods, interpretation and scoring criteria used ${ }^{8-24}$ (Buza et al, in press).

Serous endometrial carcinoma is the most biologically aggressive variant of endometrial cancer with a high recurrence rate and relative resistance to conventional chemotherapy, presenting a significant therapeutic challenge to oncologists. ${ }^{25-27}$ In the era of precision cancer therapy, there is a pressing need to identify more effective, targeted treatment for patients with serous carcinoma to reduce the mortality and potentially reduce the morbidity associated with traditional therapies. The reported high rates of HER2 overexpression in endometrial serous carcinoma and the clinical success of HER2-based therapies in other malignancies would make HER2 a promising drug target.

Although in vivo clinical activity of trastuzumab (monoclonal antibody against HER2/neu) has been demonstrated in case reports of recurrent endometrial carcinoma, ${ }^{12,28,29}$ to date no significant benefit was observed in clinical trials. ${ }^{30}$ The results of these trials, however, have been criticized primarily on the basis of patient selection. ${ }^{31}$ The importance of appropriate pre-selection of patients in clinical trials evaluating targeted therapies have been emphasized by experts, arguing that using a therapeutic agent in an unselected patient population may potentially lead to incorrect classification of a drug as inactive. ${ }^{32}$ A randomized phase II study is currently enrolling patients at multiple institutions in the United States evaluating carboplatin/paclitaxel with or without trastuzumab in patients with advanced or recurrent HER2-positive$3+$ immunohistochemistry or FISH amplifiedendometrial serous carcinoma (NCT01367002). Pathologists have a pivotal role in the patient selection process by evaluating the HER2 status of tumors; therefore, standardized endometrial cancerspecific testing, scoring and reporting guidelines need to be developed.

This study was designed to systemically evaluate HER2 overexpression and amplification based on our 4-year experience of HER2 testing of endometrial serous carcinoma and to develop specific recommendations for assessing the HER2 status in endometrial cancers.

\section{Materials and methods}

Text search for endometrial serous carcinoma cases with known HER2 status between July 2008 and August 2012 was performed in our departmental archives. All H\&E and immunohistochemical slides were reviewed by two gynecologic pathologists (NB and PH). Tumor stage (per FIGO 2009) and HER2 FISH results were obtained from surgical pathology reports. Herceptest Kit (DAKO, Carpinteria, CA, USA) was used for HER2 immunohistochemical stain in all cases, and PathVysion (Abbott) Kit was used for HER2 FISH evaluation of all cases with an original immunohistochemical score of $2+$ and in a small number of immunohistochemical scores of 0 , $1+$ and $3+$ cases.

HER2 immunohistochemical slides were systematically reviewed-blinded to the originally reported HER2 scores and FISH results-to assess the percentage of tumor cells with complete and incomplete membrane staining, staining intensity (weak, moderate, strong) and staining heterogeneity. Immunohistochemical staining heterogeneity was defined by the presence of at least two-degree difference in staining intensity (none to moderate, weak to strong or none to strong) involving at least $5 \%$ of tumor cells. HER2 scores were reassigned both per the original United States Food and Drug Administration (FDA) criteria (previous breast scoring criteria ${ }^{33}$ and per the current American Society of Clinical Oncology (ASCO)/College of American Pathologists (CAP) guidelines for breast cancer $^{4}$ (Table 1). HER2 amplification by FISH was defined as HER2 to chromosome enumeration probe 17 (CEP17) ratio of $\geq 2.0$. Clinical information was retrieved from the patients' medical records. Chi-square test was used for statistical analysis. A $P$ value of $<0.05$ was considered statistically significant.

\section{Results}

A total of 108 endometrial carcinomas were included in the final study cohort, including 85 pure serous carcinomas and 23 mixed endometrial carcinomas with a serous component. Fifty-two of these cases (48\%) had available HER2 FISH results, including all HER2 immunohistochemistry $2+$ cases.

Thirty-eight cases $(35 \%$; 38/108) had HER2 overexpression either by the FDA or ASCO/CAP 2007 scoring criteria-and/or gene amplification by FISH (Table 2, Figure 1). Five of these 38 cases $(13 \%)$ showed discrepant immunohistochemical scores when using the FDA versus the ASCO/CAP scoring criteria: 30 were scored as $3+$ per the FDA, whereas only 25 cases fell in that category based on the new ASCO/CAP guidelines and the remaining 5 cases were scored as $2+$, as the percentage of tumor cells with intense membrane staining fell between 10 and $30 \%$.

The overall concordance rate between HER2 immunohistochemistry and FISH was $75 \%$ (39 of 52 cases) when using the FDA criteria, compared with $81 \%$ (42 of 52 cases) for the ASCO/CAP scoring system (Tables 2 and 3). However, when the HER2 immunohistochemistry $2+$ cases were excluded, the concordance rates increased to $78 \%(28 / 36)$ using the FDA criteria and $86 \%(25 / 29)$ using the ASCO/CAP criteria. Tumors with equivocal $(2+)$ HER2 immunohistochemical scores showed HER2 gene amplification in $31 \%(5 / 16)$ and $26 \%(6 / 23)$ of cases when using the FDA and ASCO/CAP scoring criteria, respectively. 
Table 3 provides detailed information on cases with discordant HER2 immunohistochemistry and FISH results. Three cases (case nos. 1, 2 and 3) with an immunohistochemical score of $1+$ (by both scoring criteria) were amplified by FISH (HER2/ CEP17 ratios ranging from 2 to 2.6). Five cases with a HER2 $3+$ immunohistochemical score per the FDA criteria and one $3+$ immunohistochemistry case per the ASCO/CAP criteria had no HER2 gene amplification by FISH (HER2/CEP17 ratios ranging from 0.85 to 1.7). Four of these cases (case nos. 9, 11, 12 and 13) showed significant heterogeneity of HER2 protein expression by immunohistochemistry, which may have contributed to the discordant FISH results. Similarly, three of the $2+$ immunohistochemistry (by both scoring criteria) cases (case nos. 4, 5 and 7) with HER2 gene amplification demonstrated heterogeneous HER2 protein expression.

Heterogeneous HER2 protein expression by immunohistochemistry was present in 33 cases (31\%), including 20 HER2-positive cases (20/38; $53 \%)$ and 13 HER2-negative cases (13/70; 19\%) (Table 4). The percentage of cells with strong, complete membrane staining in cases with heterogeneity ranged between 5 and $80 \%$. Lateral or basolateral ('U-shaped') membranous protein expression pattern-resulting from lack of apical stainingwas encountered (at least focally) in majority of the HER2-positive cases (74\%; 28/38 cases) where the tumor demonstrated a glandular (or 'pseudoglandular') architecture (Figure 2). By contrast, cases with a complete membranous staining pattern generally had a solid growth pattern.
Mixed endometrial carcinomas with a serous component were found to be less frequently HER2 positive than pure serous carcinoma (22 versus $39 \%$, respectively), although the difference did not reach statistical significance $(P=0.064)$. Four of the five HER2-positive mixed endometrial tumors had HER2 immunostaining available on the non-serous components. One of these cases showed a $3+$ immunohistochemical score (by both scoring criteria) in the non-serous (endometrioid and undifferentiated carcinoma) component, similar to the serous component. Two cases showed decreased immunostaining

Table 2 HER2 immunohistochemical score distribution and correlation with HER2 FISH results

\begin{tabular}{|c|c|c|c|c|}
\hline $\begin{array}{l}\text { HER2 } \\
\text { IHC score }\end{array}$ & $\begin{array}{c}\text { FDA scoring } \\
\text { criteria, } \mathrm{n}\end{array}$ & $\begin{array}{c}\text { FISH } \\
\text { amplified, } \mathrm{n}\end{array}$ & $\begin{array}{c}\text { FISH not } \\
\text { amplified, } \mathrm{n}\end{array}$ & $\begin{array}{c}\text { FISH not } \\
\text { done, } \mathrm{n}\end{array}$ \\
\hline 0 & 19 & 0 & 4 & 15 \\
\hline $1+$ & 43 & 3 & 14 & 26 \\
\hline $2+$ & 16 & 5 & 11 & 0 \\
\hline $3+$ & 30 & 10 & 5 & 15 \\
\hline $\begin{array}{l}\text { HER2 } \\
\text { IHC score }\end{array}$ & $\begin{array}{c}\text { ASCO/CAP } \\
\text { scoring } \\
\text { criteria, } \mathrm{n}\end{array}$ & $\begin{array}{c}\text { FISH } \\
\text { amplified, } \\
\mathrm{n}\end{array}$ & $\begin{array}{c}\text { FISH not } \\
\text { amplified, } \mathrm{n}\end{array}$ & $\begin{array}{c}\text { FISH not } \\
\text { done, } \mathrm{n}\end{array}$ \\
\hline 0 & 17 & 0 & 3 & 14 \\
\hline $1+$ & 43 & 3 & 13 & 27 \\
\hline $2+$ & 23 & 6 & 17 & 0 \\
\hline $3+$ & 25 & 9 & 1 & 15 \\
\hline
\end{tabular}

Abbreviations: ASCO, American Society of Clinical Oncology; CAP, College of American Pathologists; FDA, Food and Drug Administration; FISH, fluorescent in situ hybridization; IHC, immunohistochemistry.

Table 1 Comparison of HER2 immunohistochemistry scoring criteria in breast and gastric cancer

\begin{tabular}{|c|c|c|c|}
\hline $\begin{array}{l}\text { IHC } \\
\text { score }\end{array}$ & $\begin{array}{l}\text { Breast Ca (FDA; Herceptest package } \\
\text { insert) }\end{array}$ & Breast Ca (ASCO/CAP 2007) & Gastric/GEJ Ca (ToGA trial) \\
\hline 0 & $\begin{array}{l}\text { No staining is observed, or membrane } \\
\text { staining is observed in }<10 \% \text { of } \\
\text { tumor cells }\end{array}$ & $\begin{array}{l}\text { No staining is observed in invasive tumor } \\
\text { cells }\end{array}$ & $\begin{array}{l}\text { No reactivity, or membranous reactivity in } \\
<10 \% \text { of cells (resections) or in }<5 \\
\text { clustered tumor cells (biopsies) }\end{array}$ \\
\hline $1+$ & $\begin{array}{l}\text { Faint/barely perceptible membrane } \\
\text { staining in > } 10 \% \text { of tumor cells. The } \\
\text { cells exhibit incomplete membrane } \\
\text { staining }\end{array}$ & $\begin{array}{l}\text { Weak, incomplete membrane staining in } \\
\text { any proportion of invasive tumor cells or } \\
\text { weak, complete membrane staining in } \\
<10 \% \text { of cells }\end{array}$ & $\begin{array}{l}\text { Faint/barely perceptible membrane staining } \\
\text { in } \geq 10 \% \text { of tumor cells; cells are only } \\
\text { reactive in part of their membrane } \\
\text { (resections). Tumor cell cluster ( } \geq 5 \text { cells) } \\
\text { with a faint/barely perceptible membranous } \\
\text { reactivity (biopsies) }\end{array}$ \\
\hline $2+$ & $\begin{array}{l}\text { Weak-to-moderate complete } \\
\text { membrane staining in }>10 \% \text { of tumor } \\
\text { cells }\end{array}$ & $\begin{array}{l}\text { Complete membrane staining that is non- } \\
\text { uniform or weak but with obvious } \\
\text { circumferential distribution in at least } 10 \% \\
\text { of cells or intense complete membrane } \\
\text { staining in } \leq 30 \% \text { of tumor cells }\end{array}$ & $\begin{array}{l}\text { Weak-to-moderate complete, basolateral or } \\
\text { lateral membranous reactivity in } \geq 10 \% \text { of } \\
\text { tumor cells (resections) or in a tumor cell } \\
\text { cluster ( } \geq 5 \text { cells) (biopsies) }\end{array}$ \\
\hline $3+$ & $\begin{array}{l}\text { Strong, complete membrane staining } \\
\text { in }>10 \% \text { of tumor cells }\end{array}$ & $\begin{array}{l}\text { Uniform intense membrane staining in } \\
>30 \% \text { of invasive tumor cells }\end{array}$ & $\begin{array}{l}\text { Strong complete, basolateral or lateral } \\
\text { membranous reactivity in } \geq 10 \% \text { of tumor } \\
\text { cells (resections). } \\
\text { Tumor cell cluster ( } \geq 5 \text { cells) with a strong } \\
\text { complete, basolateral or lateral } \\
\text { membranous staining, irrespective of the } \\
\text { percentage of tumor cells stained (biopsies) }\end{array}$ \\
\hline
\end{tabular}

Abbreviations: ASCO, American Society of Clinical Oncology; CAP, College of American Pathologists; FDA, Food and Drug Administration; GEJ, gastro-esophageal junction; IHC, immunohistochemistry; ToGA, Trastuzumab for gastric cancer. 

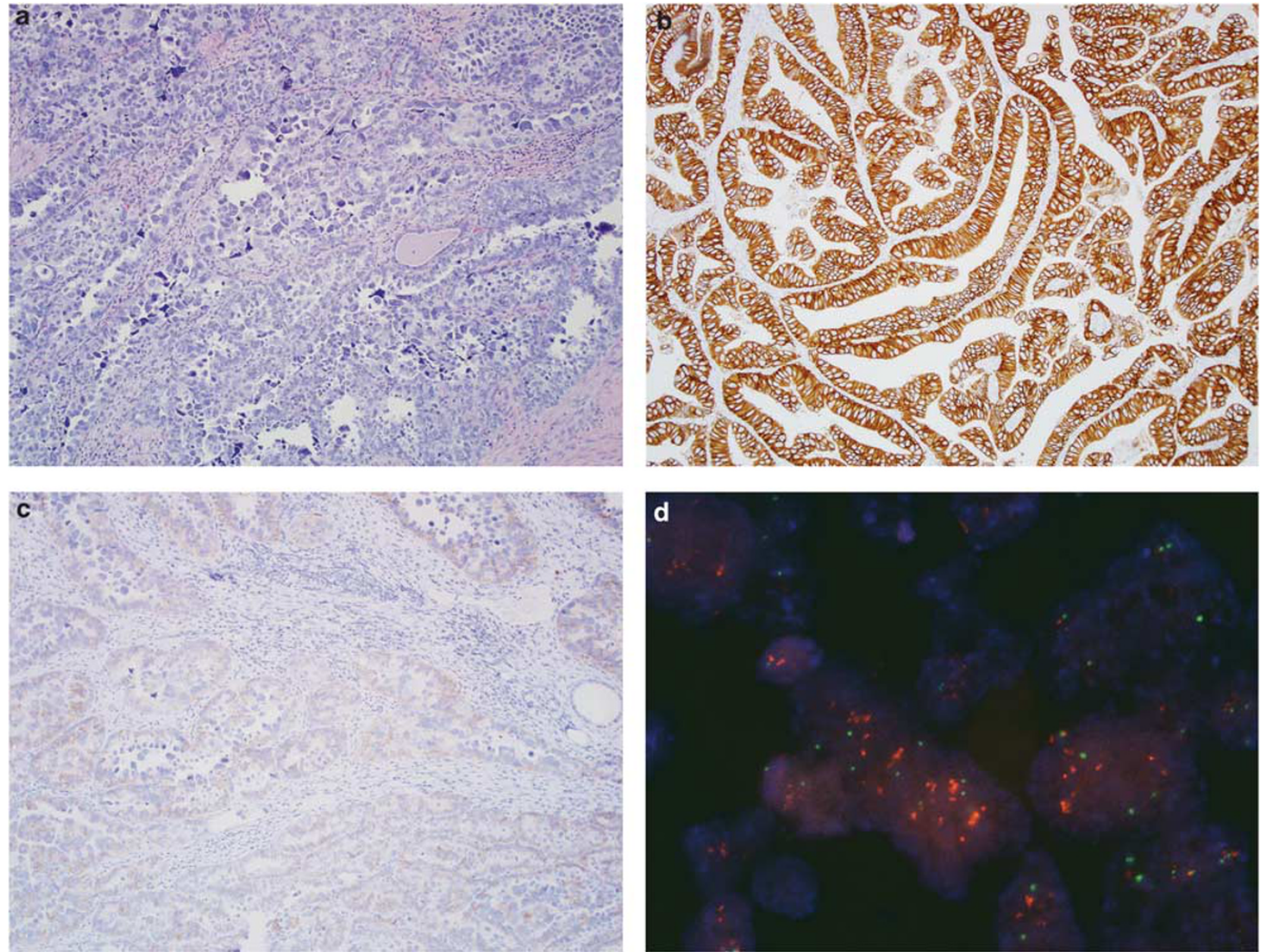

Figure 1 Histomorphology, HER2 protein expression and HER2 gene amplification in endometrial serous carcinoma. (a) Characteristic morphology of serous carcinoma, displaying predominantly glandular architecture with high grade nuclei (H\&E stain). (b) Diffuse complete and basolateral membranous HER2 immunostaining ( $3+$ ). (c) Weak, incomplete membranous HER2 immunostaining in $>10 \%$ of tumor cells $(1+)$. (d) HER2 gene amplification by FISH; HER2:CEP17 ratio = 3.4.

$(2+$ by both scoring criteria) in the non-serous (undifferentiated and clear cell) components compared with the serous carcinoma $(3+)$. One tumor had a HER2-positive endometrioid $(3+)$ component and decreased staining of the undifferentiated component $(2+$ by both scoring criteria). No significant difference was observed in the HER2 staining intensity between the different components of the HER2-negative mixed tumors.

No significant statistical correlation was observed between the patients' ethnic origin or tumor stage and HER2 status $(P=0.098$ and 0.384 , respectively; Tables 5 and 6).

\section{Discussion}

The current study constitutes the largest series of comprehensive, systematic evaluation of HER2 status in endometrial serous carcinoma to date, with two major findings of clinical relevance: (1) an overall $35 \%$ of cases had HER2 protein overexpression and/or gene amplification; and (2) heterogeneity of HER2 protein expression was observed in $53 \%$ of immunohistochemistry-positive cases, which has not been previously reported in the literature.

Previous studies evaluating the HER2 status in endometrial carcinomas suffered from several limitations, including inappropriate case selection and lack of standardized HER2 testing and scoring criteria, leading to a wide range-14-80\%-of reported HER2 positivity in endometrial serous carcinoma $^{8-24}$ (Buza et al, in press). One of the largest studies-a phase II clinical trial of singleagent trastuzumab in advanced or recurrent endometrial carcinoma-for example, has been previously criticized for including a large number of type I and mixed endometrial carcinomas, and the histological subtype was not specified in nearly half of the cases. ${ }^{30,31}$ Many other studies also included various histological subtypes and grades of endometrial carcinoma, and even malignant mixed mullerian tumors (carcinosarcomas) in the 
Table 3 HER2-positive cases with discrepant HER2 immunohistochemistry and FISH results

HER2 IHC

HER2 FISH

\begin{tabular}{|c|c|c|c|c|c|c|c|c|c|c|c|c|}
\hline \multirow[b]{2}{*}{$\begin{array}{l}\text { Case } \\
\text { No. }\end{array}$} & \multirow[b]{2}{*}{ Race } & \multirow[b]{2}{*}{$\begin{array}{c}\text { Age } \\
\text { (year) }\end{array}$} & \multirow[b]{2}{*}{ Histology } & \multirow[b]{2}{*}{$\begin{array}{l}\text { FIGO } \\
\text { stage }\end{array}$} & & & & & & & & \\
\hline & & & & & $\begin{array}{l}\% \text { Complete } \\
\text { membrane } \\
\text { staining }\end{array}$ & $\begin{array}{c}\% \\
\text { Incomplete } \\
\text { staining }\end{array}$ & $\begin{array}{l}\text { Staining } \\
\text { intensity }\end{array}$ & Heterogeneity & $\begin{array}{c}\text { HER2 } \\
\text { score } \\
(F D A)\end{array}$ & $\begin{array}{c}\text { HER2 } \\
\text { score } \\
(A S C O / \\
\text { CAP) }\end{array}$ & Amplification & $\begin{array}{l}\text { HER2/ } \\
\text { CEP17 } \\
\text { ratio }\end{array}$ \\
\hline 1 & $\mathrm{C}$ & 81 & SC & 1 & 0 & $10 \%$ & W & No & $1+$ & $1+$ & Yes & 2.6 \\
\hline 2 & $\mathrm{C}$ & 71 & SC & 4 & $0 \%$ & $80 \%$ & W & No & $1+$ & $1+$ & Yes & 2.5 \\
\hline 3 & $\mathrm{C}$ & 50 & SC & 1 & 0 & $60 \%$ & W & No & $1+$ & $1+$ & Yes & 2.0 \\
\hline 4 & $\mathrm{O}$ & 68 & SC & 3 & $10 \%$ & 0 & $\mathrm{M}$ & Yes & $2+$ & $2+$ & Yes & 3.3 \\
\hline 5 & $\mathrm{C}$ & 70 & SC & 4 & $20 \%$ & $30 \%$ & W-M & Yes & $2+$ & $2+$ & Yes & 2.0 \\
\hline 6 & $\mathrm{C}$ & 75 & SC & 1 & $90 \%$ & $10 \%$ & W-M & No & $2+$ & $2+$ & Yes & 2.7 \\
\hline 7 & $\mathrm{C}$ & 78 & SC & 4 & $30 \%$ & $50 \%$ & M & Yes & $2+$ & $2+$ & Yes & 3.4 \\
\hline 8 & $\mathrm{C}$ & 84 & SC & 3 & $20 \%$ & $80 \%$ & W-M & No & $2+$ & $2+$ & Yes & 2.1 \\
\hline 9 & $\mathrm{C}$ & 76 & SC & 1 & $\begin{array}{c}20 \% \text { S, } 70 \% \\
\text { W-M }\end{array}$ & $10 \%$ & W-S & Yes & $3+$ & $2+$ & No & 1.7 \\
\hline 10 & $\mathrm{C}$ & 61 & SC & 3 & $\begin{array}{c}50 \%(20 \% \mathrm{~S} \\
30 \% \mathrm{M})\end{array}$ & $50 \%$ & W-S & Yes & $3+$ & $2+$ & Yes & 2.5 \\
\hline 11 & $\mathrm{C}$ & 75 & SC & 4 & $15 \%$ & $85 \%$ & W-S & Yes & $3+$ & $2+$ & No & 0.85 \\
\hline 12 & AA & 62 & SC & 3 & $15 \%$ & $85 \%$ & W-S & Yes & $3+$ & $2+$ & No & 1.7 \\
\hline 13 & $\mathrm{C}$ & 74 & SC & 1 & $30 \%$ & $70 \%$ & M-S & Yes & $3+$ & $2+$ & No & 1.2 \\
\hline 14 & $\mathrm{C}$ & 62 & SC & 1 & $40 \%$ & $60 \%$ & S & No & $3+$ & $3+$ & No & 1.4 \\
\hline
\end{tabular}

Abbreviations: AA, African-American; ASCO, American Society of Clinical Oncology; C, Caucasian; CAP, College of American Pathologists; FDA, Food and Drug Administration; FISH, fluorescent in situ hybridization; IHC, immunohistochemistry; M, moderate; O, other; S, strong; SC, serous carcinoma; W, weak.

Table 4 HER2 immunohistochemistry heterogeneity

\begin{tabular}{lcc}
\hline Total cases & Positive cases & Negative cases \\
\hline $33 / 108(31 \%)$ & $20 / 38(53 \%)$ & $13 / 70(19 \%)$ \\
\hline
\end{tabular}

same analysis, making the interpretation of data difficult. ${ }^{14-16,34,35}$ Several previous studies used non-FDA-approved HER2 antibodies, ie, c-erbB-2 clone A0485 (DAKO), ${ }^{24,35,36}$ c-erbB-2/ Her-2/neu Ab17 (monoclonal antibodies e2-4001 and 3B5; Neomarkers) ${ }^{8}$ and clone TAB250 (Zymed). ${ }^{16,35}$ Although most studies used the FDA scoring criteria for HER2 immunohistochemistry, $8,9,13-15,18,22,24,30,35,36$ many of them considered both the $2+$ and $3+$ immunohistochemical scores positive for HER2 overexpression. ${ }^{8,13,15,30,35,36}$ Others used selfdeveloped semiquantitative immunohistochemical scoring systems, not currently approved for any other tumor types. ${ }^{10,12,16,20}$ Application of the updated breast HER2 immunohistochemical scoring system (ASCO/CAP 2007) has not been previously assessed in endometrial cancer.

In this study we used standard FDA-approved test kits-Herceptest and PathVysion-for systematic evaluation of the HER2 status on whole tumor tissue sections and compared the original (FDA approved) and the new (ASCO/CAP 2007) breast cancer HER2 scoring criteria, in addition to assessing the membrane staining pattern and tumor heterogeneity of HER2 expression. Overall, more than one-third
(35\%) of endometrial serous carcinomas were HER2 positive scored by immunohistochemistry and/or FISH. Concordance rates between HER2 immunohistochemistry and FISH have been calculated based on the limited FISH data available. The highest concordance rate-excluding the immunohistochemistry $2+$ equivocal cases-86\% was observed between HER2 immunohistochemistry and FISH when using the 2007 ASCO/CAP criteria, compared with a $78 \%$ concordance rate when the FDA guidelines were applied. Although using the ASCO/CAP guidelines appears to provide better concordance between immunohistochemistry and FISH than the FDA criteria, it falls below the reported concordance rates of breast cancer. ${ }^{4}$

Characteristics of HER2 amplification/overexpression may vary significantly according to the tumor type and primary site. HER2 overexpression and amplification are relatively uniform throughout the tumor tissue in breast cancer, and tumor heterogeneity of the HER2 status is considered a rare event. ${ }^{37,38}$ Gastric and gastro-esophageal junction carcinomas, on the other hand, show significant intratumoral heterogeneity of HER2 status, reported in nearly half of the cases. ${ }^{39,40}$ This phenomenon led to specific HER2 scoring guidelines in gastric biopsy specimens, allowing for a $3+$ HER2 immunohistochemical score if any tumor cell clusters show strong membranous staining, regardless of the percentage of positive cells. ${ }^{7}$ Similar to gastric cancer, endometrial serous carcinoma in our series demonstrated significant heterogeneity of HER2 expression by immunohistochemistry in 53\% 


HER2 testing of endometrial serous carcinoma
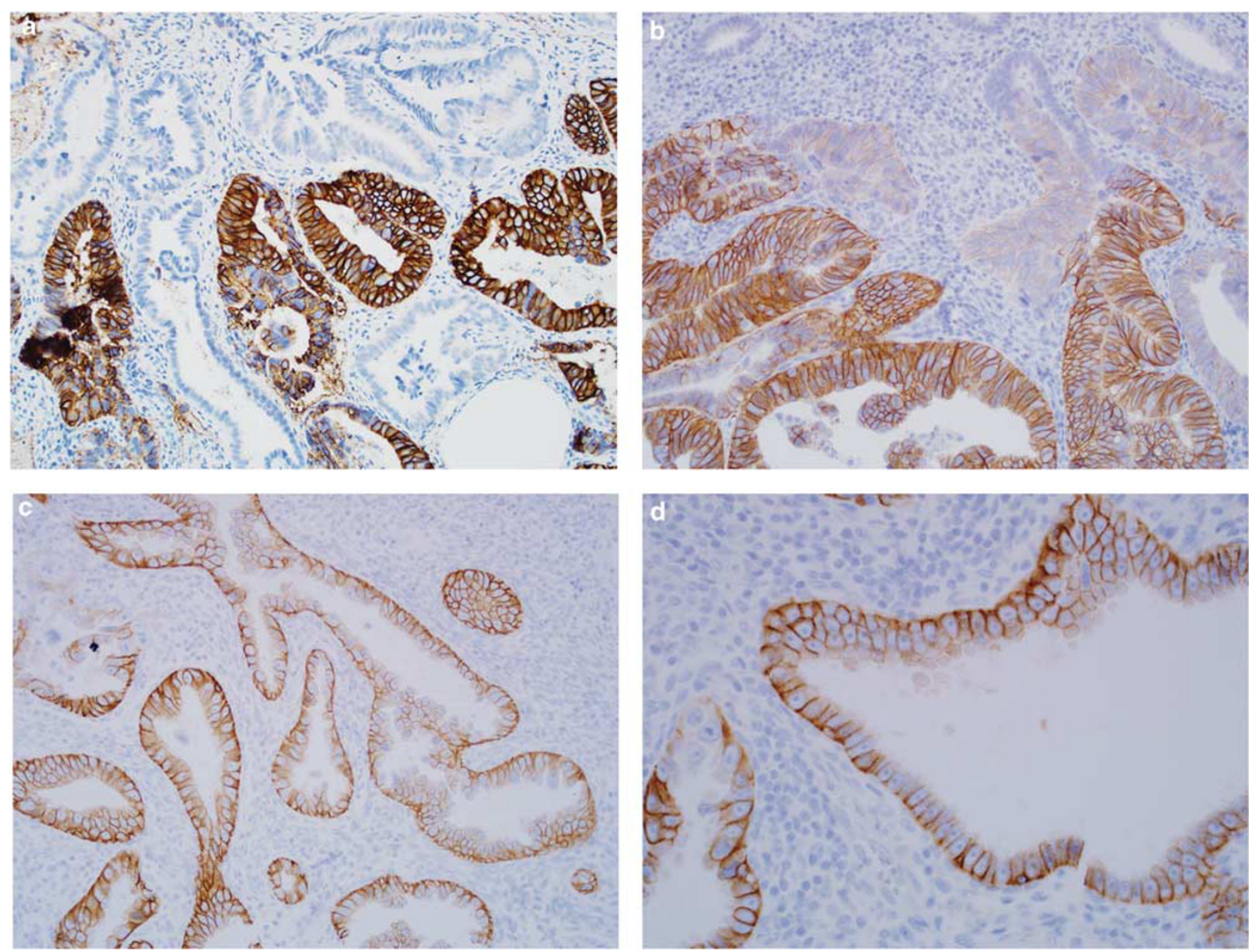

Figure 2 Tumor heterogeneity and membrane staining pattern of HER2 immunohistochemistry in endometrial serous carcinoma. (a, b) Heterogeneous HER2 expression in serous carcinoma. (c-d) Lack of apical HER2 immunostaining results in a lateral or basolateral ('U-shaped') staining pattern.

Table 5 Correlation between HER2 status and patient ethnic origin

White/Caucasian, n (\%) African-American, n (\%) Hispanic, n (\%) Asian, n (\%) Other, n (\%) NA, n (\%)

\begin{tabular}{|c|c|c|c|c|c|c|}
\hline HER2 positive $(n=38)$ & $31(81.5 \%)$ & $4(10.5 \%)$ & $0(0 \%)$ & $1(2.6 \%)$ & $1(2.6 \%)$ & $1(2.6 \%)$ \\
\hline HER2 negative $(n=70)$ & $50(71.4 \%)$ & $14(20 \%)$ & $3(4.3 \%)$ & $0(0)$ & $3(4.3 \%)$ & $0(0)$ \\
\hline
\end{tabular}

Abbreviation: NA, not available.

Table 6 Correlation between HER2 status and tumor stage

\begin{tabular}{|c|c|c|c|c|c|}
\hline & Stage I, n (\%) & Stage II, n (\%) & Stage III, n (\%) & Stage IV, n (\%) & Stage NA, n (\%) \\
\hline HER2 positive $(n=38)$ & $24(63.2 \%)$ & $1(2.6 \%)$ & $6(15.8 \%)$ & $7(18.4 \%)$ & $0(0)$ \\
\hline HER2 negative $(n=70)$ & $44(62.8 \%)$ & $4(5.7 \%)$ & $12(17.1 \%)$ & $8(11.4 \%)$ & $2(2.8 \%)$ \\
\hline
\end{tabular}

Abbreviation: NA, not available.

of the HER2-positive cases. Our data on heterogeneity could potentially argue for similar recommendations in endometrial carcinoma, although the tissue sampling tends to be more multifocal in endometrial biopsies and curettings than in typical gastric biopsies. The presence of significant tumor heterogeneity in endometrial serous carcinoma requires selection of larger tumor tissue samples for HER2 testing. Previous investigations analyzing small areas of tumor cells-including a tissue 
microarray study ${ }^{11}$ —were unable to sufficiently address issues, such as tumor heterogeneity.

Assignments of the FDA and/or ASCO/CAP immunohistochemical scores were problematic in a few of our cases, mainly due to the presence of incomplete moderate or strong membranous staining, which is not specified under either scoring category in breast cancer. When assessing the membrane staining pattern in endometrial serous carcinoma, we found that in contrast to the complete membranous staining of breast carcinomas, large proportion (74\%) of HER2-positive serous endometrial tumors lacked staining (at least focally) on their apical membrane surfaces, resulting in a lateral or basolateral ('U-shaped') pattern, much like that of previously observed in gastric/gastro-esophageal junction carcinomas. ${ }^{7}$ Tumors with this type of lateral/basolateral staining pattern had a predominantly glandular (or 'pseudo-glandular') architecture, while those with a more solid growth displayed complete membranous HER2 immunostaining.

In conclusion, the current ASCO/CAP breast scoring criteria provide better concordance between immunohistochemistry and FISH than the FDA scoring criteria in serous endometrial carcinoma. Assessment of HER2 immunohistochemistry preferably on multiple different tumor sections or sections with large tumor areas is recommended, due to the presence of significant heterogeneity of HER2 protein expression observed in this study. Tumors with loss of apical HER2 immunostaining and strong lateral/basolateral membranous staining pattern should also be allowed for a $3+$ HER2 immunohistochemical score. Evaluation of larger tumor area $\left(\sim 1 \mathrm{~cm}^{2}\right)$ for HER2 FISH is preferred, and correlation with the highest HER2 protein expression by immunohistochemistry is recommended.

Future studies-including a current multiinstitutional randomized phase II clinical trial (NCT01367002) - are necessary to correlate the HER2 expression/amplification results with therapeutic response.

\section{Disclosure/conflict of interest}

The authors declare no conflict of interest.

\section{References}

1 Slamon DJ, Clark GM, Wong SG, et al. Human breast cancer: correlation of relapse and survival with amplification of the HER-2/neu oncogene. Science 1987;235:177-182.

2 Kunz PL, Mojtahed A, Fisher GA, et al. HER2 expression in gastric and gastroesophageal junction adenocarcinoma in a US population: clinicopathologic analysis with proposed approach to HER2 assessment. Appl Immunohistochem Mol Morphol 2012;20: 13-24.
$3 \mathrm{Hu}$ Y, Bandla S, Godfrey TE, et al. HER2 amplification, overexpression and score criteria in esophageal adenocarcinoma. Mod Pathol 2011;24:899-907.

4 Wolff AC, Hammond ME, Schwartz JN, et al. American Society of Clinical Oncology/College of American Pathologists guideline recommendations for human epidermal growth factor receptor 2 testing in breast cancer. Arch Pathol Lab Med 2007;131:18-43.

5 Albarello L, Pecciarini L, Doglioni C. HER2 testing in gastric cancer. Adv Anat Pathol 2011;18:53-59.

6 Bang YJ, Van Cutsem E, Feyereislova A, et al. Trastuzumab in combination with chemotherapy versus chemotherapy alone for treatment of HER2-positive advanced gastric or gastro-oesophageal junction cancer (ToGA): a phase 3, open-label, randomised controlled trial. Lancet 2010;376:687-697.

7 Ross JS, Mulcahy M. HER2 testing in gastric/ gastroesophageal junction adenocarcinomas: unique features of a familiar test. Gastrointest Cancer Res 2011;4:62-66.

8 Slomovitz BM, Broaddus RR, Burke TW, et al. Her-2/ neu overexpression and amplification in uterine papillary serous carcinoma. J Clin Oncol 2004;22: 3126-3132.

9 Santin AD, Bellone S, Van Stedum S, et al. Determination of HER2/neu status in uterine serous papillary carcinoma: comparative analysis of immunohistochemistry and fluorescence in situ hybridization. Gynecol Oncol 2005;98:24-30.

10 Rolitsky CD, Theil KS, McGaughy VR, et al. HER-2/neu amplification and overexpression in endometrial carcinoma. Int J Gynecol Pathol 1999;18:138-143.

$11 \mathrm{Xu} \mathrm{M}$, Schwartz P, Rutherford T, et al. HER-2/neu receptor gene status in endometrial carcinomas: a tissue microarray study. Histopathology 2010;56: 269-273.

12 Villella JA, Cohen S, Smith DH, et al. HER-2/neu overexpression in uterine papillary serous cancers and its possible therapeutic implications. Int J Gynecol Cancer 2006;16:1897-1902.

13 Togami S, Sasajima Y, Oi T, et al. Clinicopathological and prognostic impact of human epidermal growth factor receptor type 2 (HER2) and hormone receptor expression in uterine papillary serous carcinoma. Cancer Sci 2012;103:926-932.

14 Morrison C, Zanagnolo V, Ramirez N, et al. HER-2 is an independent prognostic factor in endometrial cancer: association with outcome in a large cohort of surgically staged patients. J Clin Oncol 2006;24:2376-2385.

15 Grushko TA, Filiaci VL, Mundt AJ, et al. An exploratory analysis of HER-2 amplification and overexpression in advanced endometrial carcinoma: a Gynecologic Oncology Group study. Gynecol Oncol 2008;108:3-9.

16 Halperin R, Zehavi S, Habler L, et al. Comparative immunohistochemical study of endometrioid and serous papillary carcinoma of endometrium. Eur J Gynaecol Oncol 2001;22:122-126.

17 Santin AD, Bellone S, Gokden M, et al. Overexpression of HER-2/neu in uterine serous papillary cancer. Clin Cancer Res 2002;8:1271-1279.

18 Santin AD, Bellone S, Siegel ER, et al. Racial differences in the overexpression of epidermal growth factor type II receptor (HER2/neu): a major prognostic indicator in uterine serous papillary cancer. Am J Obstet Gynecol 2005;192:813-818.

19 El-Sahwi KS, Schwartz PE, Santin AD. Development of targeted therapy in uterine serous carcinoma, a 
biologically aggressive variant of endometrial cancer. Expert Rev Anticancer Ther 2012;12:41-49.

20 Khalifa MA, Mannel RS, Haraway SD, et al. Expression of EGFR, HER-2/neu, P53, and PCNA in endometrioid, serous papillary, and clear cell endometrial adenocarcinomas. Gynecol Oncol 1994;53:84-92.

21 Prat J, Oliva E, Lerma E, et al. Uterine papillary serous adenocarcinoma. A 10-case study of p53 and c-erbB-2 expression and DNA content. Cancer 1994;74: 1778-1783.

22 Odicino FE, Bignotti E, Rossi E, et al. HER-2/neu overexpression and amplification in uterine serous papillary carcinoma: comparative analysis of immunohistochemistry, real-time reverse transcriptionpolymerase chain reaction, and fluorescence in situ hybridization. Int J Gynecol Cancer 2008;18:14-21.

23 Diaz-Montes TP, Ji H, Smith Sehdev AE, et al. Clinical significance of Her-2/neu overexpression in uterine serous carcinoma. Gynecol Oncol 2006;100:139-144.

24 Singh P, Smith CL, Cheetham G, et al. Serous carcinoma of the uterus-determination of HER-2/neu status using immunohistochemistry, chromogenic in situ hybridization, and quantitative polymerase chain reaction techniques: its significance and clinical correlation. Int J Gynecol Cancer 2008;18:1344-1351.

25 Sherman ME, Bitterman $\mathrm{P}$, Rosenshein NB, et al. Uterine serous carcinoma. A morphologically diverse neoplasm with unifying clinicopathologic features. Am J Surg Pathol 1992;16:600-610.

26 Hamilton CA, Cheung MK, Osann K, et al. Uterine papillary serous and clear cell carcinomas predict for poorer survival compared to grade 3 endometrioid corpus cancers. Br J Cancer 2006;94:642-646.

27 Acharya S, Hensley ML, Montag AC, et al. Rare uterine cancers. Lancet Oncol 2005;6:961-971.

28 Jewell E, Secord AA, Brotherton T, et al. Use of trastuzumab in the treatment of metastatic endometrial cancer. Int J Gynecol Cancer 2006;16:1370-1373.

29 Santin AD, Bellone S, Roman JJ, et al. Trastuzumab treatment in patients with advanced or recurrent endometrial carcinoma overexpressing HER2/neu. Int J Gynaecol Obstet 2008;102:128-131.

30 Fleming GF, Sill MW, Darcy KM, et al. Phase II trial of trastuzumab in women with advanced or recurrent, HER2-positive endometrial carcinoma: a Gynecologic
Oncology Group study. Gynecol Oncol 2010; 116:15-20.

31 Santin AD. Letter to the Editor referring to the manuscript entitled: 'Phase II trial of trastuzumab in women with advanced or recurrent HER-positive endometrial carcinoma: a Gynecologic Oncology Group study' recently reported by Fleming et al., (Gynecol Oncol., 116;15-20;2010). Gynecol Oncol 2010;118:95-96; author reply 6-7.

32 Westin SN, Broaddus RR. Personalized therapy in endometrial cancer: challenges and opportunities. Cancer Biol Ther 2012;13:1-13.

33 Fitzgibbons PL, Page DL, Weaver D, et al. Prognostic factors in breast cancer. College of American Pathologists Consensus Statement 1999. Arch Pathol Lab Med 2000;124:966-978.

34 Saffari B, Jones LA, el-Naggar A, et al. Amplification and overexpression of HER-2/neu (c-erbB2) in endometrial cancers: correlation with overall survival. Cancer Res 1995;55:5693-5698.

35 Peiro G, Mayr D, Hillemanns P, et al. Analysis of HER2/neu amplification in endometrial carcinoma by chromogenic in situ hybridization. Correlation with fluorescence in situ hybridization, HER-2/neu, p53 and Ki-67 protein expression, and outcome. Mod Pathol 2004;17:227-287.

36 Gul AE, Keser SH, Barisik NO, et al. The relationship of cerb B 2 expression with estrogen receptor and progesterone receptor and prognostic parameters in endometrial carcinomas. Diagn Pathol 2010;5:13.

37 Hanna W, Nofech-Mozes S, Kahn HJ. Intratumoral heterogeneity of HER2/neu in breast cancer-a rare event. Breast J 2007;13:122-129.

38 Greer LT, Rosman M, Mylander WC, et al. Does breast tumor heterogeneity necessitate further immunohistochemical staining on surgical specimens? J Am Coll Surg 2013;216:239-251.

39 Lee HE, Park KU, Yoo SB, et al. Clinical significance of intratumoral HER2 heterogeneity in gastric cancer. Eur J Cancer 2012;49:1448-1457.

40 Lee S, de Boer WB, Fermoyle S, et al. Human epidermal growth factor receptor 2 testing in gastric carcinoma: issues related to heterogeneity in biopsies and resections. Histopathology 2011;59: 832-840. 